\title{
THE QUASI-TOROIDAL STELLARATOR: AN INNOVATIVE CONFINEMENT EXPERIMENT
}

\author{
Final Technical Report
}

For period Mar. 15, 1998 - Sept. 14, 2000

Stephen F. Knowlton - Principal Investigator

Rex F. Gandy, Christopher Watts - Co-investigators

Physics Department
Auburn University
Auburn, AL 36849

Mar. 2005

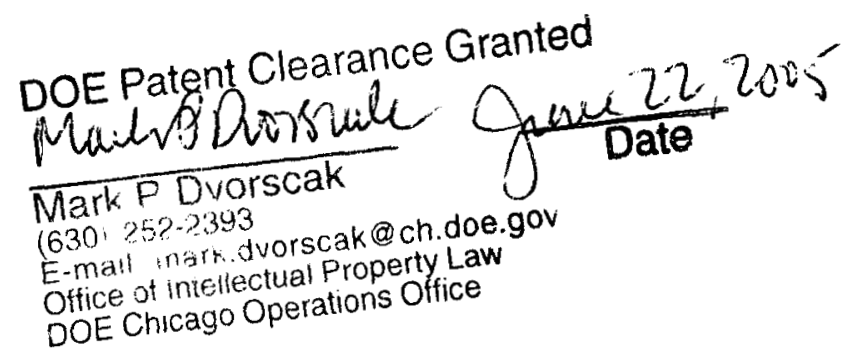

\author{
Prepared for \\ THE U.S. DEPARTMENT OF ENERGY \\ AWARD NO. DE-FG02-98ER54470
}

\section{NOTICE}

This report was prepared as an account of work sponsored by the United States Government. Neither the United States nor the United States Department of Energy, nor any of their employees, nor any of their contractors, subcontractors, or their employees, makes any warranty, express or implied, or assumes any legal liability or responsibility for the accuracy, completeness, or usefulness of any information, apparatus, product or process disclosed or represents that its use would not infringe privately-owned rights. 


\section{DISCLAIMER}

This report was prepared as an account of work sponsored by an agency of the United States Government. Neither the United States Government nor any agency Thereof, nor any of their employees, makes any warranty, express or implied, or assumes any legal liability or responsibility for the accuracy, completeness, or usefulness of any information, apparatus, product, or process disclosed, or represents that its use would not infringe privately owned rights. Reference herein to any specific commercial product, process, or service by trade name, trademark, manufacturer, or otherwise does not necessarily constitute or imply its endorsement, recommendation, or favoring by the United States Government or any agency thereof. The views and opinions of authors expressed herein do not necessarily state or reflect those of the United States Government or any agency thereof. 


\section{DISCLAIMER}

Portions of this document may be illegible in electronic image products. Images are produced from the best available original document. 


\section{Overview}

In March, 1998, Auburn University was awarded a two-year grant entitled "The Quasi-Toroidal Stellarator: an Innovative Confinement Experiment" from the Office of Fusion Energy Sciences (OFES) of DoE. The context and outcome of this grant were somewhat unusual because of its relation to work taking place elsewhere in the US fusion energy research program. The timing of this grant coincided with the beginnings of ambitious plans at Princeton Plasma Physics Laboratory (PPPL), Oak Ridge National Laboratory (ORNL), and the University of Texas to develop a new class of stellarators that exhibit improved confinement compared to conventional stellarators. This approach generally makes use of a designed symmetry of the magnetic field strength along a particular coordinate axis in the toroidal geometry of the stellarator, and is referred to as quasi-symmetry. This concept was pioneered by the Helically Symmetric Experiment (HSX) at the University of Wisconsin, which at that time was under construction and nearing completion. It has since begun began successful operation.

In 1997, the Auburn University experimental fusion research group submitted a 3year proposal for the design and construction of a small, exploratory stellarator with quasi-toroidal symmetry, based on the conceptual magnet design of Prof. P. Garabedian of New York University. While the three-year construction proposal was not accepted, the group was awarded a two-year contract to continue the design work. During this period, the Auburn team participated in an ad hoc group of university and national laboratory scientists to develop a collaborative national research plan for advanced stellarator research. What ultimately emerged from this planning effort was the US Compact Stellarator Program, in which PPPL would propose to construct a large, proofof-principle scale quasi-toroidally symmetric stellarator (now referred to as the National Compact Stellarator Experiment, or NCSX), ORNL would propose a quasi-poloidally symmetric stellarator (QPS), the University of Wisconsin would continue its HSX experiment, and Auburn would design and build a low-aspect ratio (compact) stellarator that would operate with plasma current. Its role within this integrated program was to explore aspects of current-driven magnetohydrodynamic (MHD) instabilities in stellarators that were expected to have significant consequences for the research plans of NCSX and QPS, as well as finite- $\beta$ stellarators in the international fusion research program. These included the investigation of current-driven disruptions in stellarators and their avoidance through external control of the rotational transform profile as well as the testing and validation of novel 3-D equilibrium reconstruction techniques.

Because of PPPL's intent to proceed with the design of a large quasi-toroidal stellarator with the support of OFES, the task of our two-year grant evolved away from the design of an exploratory quasi-toroidal stellarator to the planning of studies that would address some of the major physics issues that stellarators with quasi-toroidal symmetry would face, including some of the same challenges considered in our original proposed experiment. After initially considering an upgrade of our existing Compact Auburn Torsatron (CAT), we designed a new stellarator device called the Compact Toroidal Hybrid (CTH), and in Feb. 2000, submitted a proposal entitled "MHD Stability Studies of Current-Carrying plasmas in the Compact Toroidal Hybrid " to OFES in response to a competitive call for proposals. That proposal was accepted, and a new contract, DE-FG02-00ER54610 was issued to Auburn University to carry out this 
important element of the US Compact Stellarator Program. The construction of CTH is now essentially complete, and the first plasma in CTH was obtained in Feb. 2005. The quasi-toroidal NCSX experiment, to which many of our results will be delivered, is under construction at PPPL with an expected start date of 2009. Therefore, the primary result of the contract described in this final report was to support the design not of the original QUATOS device, but a stellarator of comparable scale that would investigate 3-D MHD equilibrium and instability in stellarators in the context of a collaborative, multiinstitutional program. So the intent of the proposed research that was carried out remained consistent with the original goals.

All items of equipment purchased or transferred to Auburn as part of this one-year grant remain in full use in the operating CTH experiment.

\section{Results}

In the course of this contract, members of the group wrote two journal articles on the design of their quasi-toroidal stellarator experiment, and made a number of conference presentations on the same subject. In addition, Stephen Knowlton worked for two weeks in Feb. 1999 on novel radio-frequency plasma generation techniques at the Compact Helical System (CHS), a stellarator at Nagoya University, Nagoya, Japan. The results were presented at the $12^{\text {th }}$ International Stellarator Workshop in Madison, Wisconsin in Oct. 1999, and published in the conference proceedings. The results will be useful in ongoing stellarator research, including on the present fusion experiment at Auburn.

During the latter part of the grant period, it became clear that a large, low-aspect ratio, quasi-toroidally symmetric stellarator was likely to be built at PPPL, and that this would reduce the need for a smaller-scale stellarator such as QUATOS to explore quasitoroidal symmetry. So, in coordination with the ad hoc US stellarator program plans, the effort of the Auburn University fusion laboratory shifted to developing an experiment focused on current-driven instabilities in stellarators and other issues relevant to the compact stellarator concept. The laboratory first extensively modeled studies on a prospective experiment CATSUP, an upgraded version of their existing compact torsatron CAT. Presentations were made at several conferences on the design and research plans of this upgrade. However, we soon recognized that the existing CAT device would not be reliable or well-suited for operation at higher magnetic fields $(B>$ $0.1 \mathrm{~T}$ ) or operation with ohmic plasma current. We then designed a new stellarator device that would have a larger plasma volume and higher magnetic field, but took advantage of cost-effectiveness of the CAT design and our experience in building it. This new proposed experiment was called the Compact Toroidal Hybrid (CTH) device in that it was designed to operate with plasma current, and was thus a hybrid between stellarator and tokamak. The experiment was designed with the assistance of members of the engineering staff at PPPL, and proposed to OFES in response to DOE Program Notice 00-07. The proposal was reviewed and approved for funding beginning in Oct. 2000, at which point the contract associated with this technical report was terminated.

Several items of equipment were transferred to the Auburn fusion laboratory from other DoE contractors. These include 10 flywheel motor-generators ( 8 from M.I.T.; 2 from the HSX laboratory of the University of Wisconsin) and high-voltage power supplies and capacitors from the NOVA laboratory at Lawrence Livermore National 
Laboratory. The generators are used to power the magnets of the CTH device, and the HV power supplies provide power to the RF systems for plasma production and heating. Other items were loaned from the MST laboratory of the University of Wisconsin to the QUATOS project, and are in use for similar purposes on CTH.

All funds allocated to this project were expended at the completion of the contract. 